\title{
INFLAMAÇÕES AGUDAS DOS MUSCULOS E INFECÇÕES PIOGENAS DOS OSSOS (*)
}

\author{
ARY SIQUEIRA \\ 1.0 Assistente
}

Continuando com o estudo da infecção, estudaremos na aụlà de hoje as inflamaçôes agudas dos musculos, tambem denominadas miosites - e os processos infecciosos osseos, ou sejam, as - osteites e as - ostiomielites.

\section{MIOSITES AGUDAS}

Fisiopátologia - As inflamações agudas supurativas 'dos musculos, são raramente observadas em clinica, como entidades independentes. Na maioria dos casos, as miosites parecem surgir contemporaneamente a um outro processo morbido, parecendo mesmo que os musculos são muitó refratarios á infecção. Compreende-se facilmente o porque deste fato, si dissermos que o tecido muscular é um tecido que não se presta ao desenvolvimento do processo inflamatorio, devido á sua estrutura pouco favoravel. Efetivamente, o tecido conjuntivo dos musculos se distribue entre as formações fibrosas de sustentação, bainhas e septos aponevroticos, e o sarcolema, elemento mal definido e demasiadamente unido ao material estriado, não tem tendencia a reagir independentemente. 'Podemos mesmo dizer que o tecido muscular expulsa para o tecido conjuntivo vascular frouxo, os processos inflamatorios que nele tendem a se assestar.

Por outro lado, os musculos estão adatados a grandes variações. circulatorias, apresentando estadios de hiperemia muito intensos, sem mostrar alteração de especie. Talvez devido a este fato, a hiperemia inflamatoria com todas as suas consequencias, tenha muito menor relevo no tecido muscular.

(*) Aula taquigrafada pelos alunos. 
Do que expuzemos, fica mais ou menos bem assentado que não é regra apresentar o tecido muscular, processos inflamatorios. Inversamente, é mais fréquente a presença de processos degenerativos nesse tecido, em consequencia de traumatismo, de inflamaçães nos tecidos visinhos ou, devido a infecções gerais.

Sabemos que o tecido muscular estriado tem uma labilidade toda especial, tanto assim que qualquer processo alterativo,' afeta sua estrutura e funcionalidade. Daí a razão porque sendo tã̃o raras as miosites, sejam tão frequentes as atrofias fibrosas e as degenerações -de toda a especie.

Etiologia - Para o estabelecimento de úma infecção aguda no tecido muscular, admitem-se modernamente tres principais vias de acesso:

1 - Infecção por via exogena ;

2 - Pela propagação de uma infeç̧ão nas circunvisinhanças dọ tecido muscular;

3 - Por via endogena ou hematogenica.

1 - Como tipo de uma miosite por via direta, geralmente consequente a um traumatismo, cito as - miosites supuradas post-traumaticas. Assim, são frequentes as miosites do reto anterior do abdomen, tambem denominadas - flegmões da bainha do reto -, subsequentes a apendicetomias. Trata-se em gẹral, neste caso, da contaminação da parede abdominal, pelo material ceptico contido no colon, que se infiltra na bainha do reto anterior, no momento da cauterização do coto apendicular. Na realidade, o que ha neste caso é um flegmão do tecido de enchimento da bainha do reto, ocasionando a fusão secundaria do tecido muscular.

2 - Entre as miosites por propagação, cito aquelas consequentes a ostiomielites, consecutivas a fraturas por instrumentos belicos. Nestas condiçóes, o processo supurativo difunde-se rapidamente ao longo das massas musculares que se convertem em verdadeiras bolsas de puz. Esta ocurrencia é frequente quando se trata de infecções associadas a germens anaerobios. $\mathrm{O}$ tecido muscular parece ser um excelente meio de cultivo para esse germen, como' pode muito bem ser evidenciado nas infecções gangrenosas.

3 - A infecção muscular por via hematogenica, 'pode produzirse, em primeiro lugar, devido á localização de uma pioemia, com formação de metastases. Está claro que nestes casos,. a presença de infecção.

Algumas molestias infecciosas gerais podem dar lugar, igualmente, a processos supurativos musculares. Este fato é frequentemente observado no decurso da fébre tifoide. E' bem conhecida a culos a que possue o tifo em produzir uma degeneração dos musculos abdominais anteriores, á qual da-se o nome - degeneração ce- 
rea -, de acordo com os traballhos de Virchow e Zenker. A origem desses processos supurativos é provavelmente, uma ruptura muscular, consequente ao estado de friabilidade em que se encontram os musculos afetados pelo processo degenerativo.

Identico mecanismo parecem ter certas miosites, observadas em conexão com rupturas sub-cutaneas dos musculos. $O$ foco traumatico constitue nestes casos, um terreno propicio para a fixação dos germens circulantes no sangue. Geralmente trata-se de estreptococus e e ecepcionalmente de gonococus.

Finalmente, a miosite pode apresentar-se abruptamente, sem um antecedente traumatico, e com todas as caracteristicas de uma molestia infecciosa aguda. As miosites infecciosas são relativamente frequentes no Japão, sendo que o seu quadto clinicọ é comparavel áquele da osteomielite aguda.

Sintomatologia - Os sintomas locais de todas as miosites consistem numa forte contratura do musculo atingido, que se nos mostra á palpaçã̃o, inchado e endurecido.

$\mathrm{Na}$ maioria dos casos o processo evolue para a fibrose, total ou parcial, do musculo, que se converte num tecido rigido e inextensivel.

As fases finais dos processos supurativos musculares, dão lugar a um abcesso profundo, que tende a infiltrar-se no tecido celular circunjacente.

Tratamento - Pelo que foi visto até aqui, concluimos que as miosites são processos de pequena importancia e de tratamento relativamente facil.

A terapeutica mais aconselhavel é colocar o musculo afetado em repouso, aplicar sobre ele compressas humidas e diatermiá.

As miosites infecciosas mais frequentes entre nós são- devidas na maioria das vezes ao treponema pallidum, regredindo facilmente pela medicação especifica.

\section{OSTEITES E OSTEOMIELITES}

Fisiopatologia - A séde do processo inflamatorio nos ossos, á semelhança do que se dá para a generalidade dos tecidos, é o tecido conjuntivo e o tecido vascular. Este sistema vasculo-conjuntivo, encontra-se representado nos ossos, por duas formações distintas, a saber: 1) aquela que ocupa os canais de Havers, tendo por função a manutenção da vitalidade ossea; 2) aquela que forma o reticulo da medula ossea, cuja função primacial é a hematopoiese.

De acordo com essa estrutura, as infecçóes osseas localizam-se sempre no tecido conetivo Haversiano, ou na cavidade medular. Porém, somente no caso da infecção se localizar nos sistemas haversianos, pode-se falar de uma osteite. A infecção da medula, denominada - mielite ou medulite - si bem que seja uma infecção do tecido osseo, isto é, de um tecido contido no osso, é extranha a ele. 
De qualquer maneira, a infeç̧ão dos dois sistemas constitutivos dos ossos, verifica-se, na generalidade dos casos simultaneamente. Isto não implica afirmar que existe uma continuidade anatomica entre esses dois sistemas, como acreditam muitos autores; o que ha na realidade é uma continuidade vascular, que explica a inflamação paralela do tecido conjuntivo haversiano e da medula. Daí, com maior propriedade, dever-se empregar o termo - osteomielite - , que indica essa dupla localização das infecções osseas.

Etiologia - Na imensa maioria dos casos, os processos infecciosos localizam-se na medula ossea; porém, é no tecido intrahaversiano que irão se desenvolver as primeiras manifestações dos mesmos. Efetivamente, a infecção pode atingir um caso, a exemplo do que se tem visto para os outros casos, por duas vias: a) exogena e, b) endogena.

Um exemplo tipico de uma infecção exogena é aquele que leva consigo um projetil alojado no osso. Tambem por via direta produzem-se as ostiomielites das costelas, que sobrevem como complicação das resecções costais, no caso de um empiema por exemplo. Do mesmo modo, devem-se a uma propagação direta, as osteomielites das falanges ungueais, consecutivas a infecções do tecido conjuntivo da matriz da unha; que está em intimo contato com as falanges.

A regra porem, é que a infecção atinja o osso por via endogena, quer dizer, por via hematogenica, já que a medula ossea não possue vasos linfaticos. Trata-se nestes casos, geralmente, da fixação nos capilares medulares, dos germens circulantes. Estes germens, provem quasi sempre, do revestimento cutaneo-mucoso, tendo penetrado no sangue á custa de soluções de continuidade ou de processos infecciosos dos mesmos.

A presença de tais germens no sangue, traduz em alguns casos, uma verdadeira pioemia, e a ostiomelite nada mais representa aqui, sinão uma das localizações metastaticas desta infecção maciça.

Outras infecções osseas, são consequencias de uma septicemia, isto é, de uma verdadeira molestia bacteriana do sangue, uma febre tifoide por exemplo, com colonização secundaria dos germens, na
medula.

Entretanto, na maioria das vezes, a presença dos germens no sangue passa inteiramente desapercebida e a osteomielite se apresenta abruptamente, pela detenção destes germens no tecido medular, e posterior desenvolvimento de uma inflamação.

A que será devida desta localização medular? Costuma-se dizer que a medula atrae os germens cirulantes, constituindo para eles um ponto de fixação, como o são os ganglios linfaticos para os germens que circulam na linfa. E' possivel que assim seja, si levarmos em consideração a grande vivacidade do tecido histiocitario da medula. que ocorre na adolescencia, é quando são mais frequentes as ostio- 
mielites. Este processo, contrariamente, è muito menos comum na idade adulta, isto é, quando a medula se torna rica em tecido gorduroso e inativa na sua maior extensão. Como quer que seja, não ha nenhụma demonstração positiva da chamada - ação fixadora da medula -.

Com maiores provas' de veracidade, tem-se atribuido a localização medular das infecções a fatores circulatorios. Os trabalhos de Lexer acerca da vascularização dos ossos, expliçam as condições especiais que oferecem certas zonas do tecido osseo, para a embolização de pequenas massas de germens circulantes. Estas zonas são aquelas que corfespondem ás arborizações terminais da arteria nutriente do osso; ás custas dessas arborizações, estabelece-se a comunicação entre o sistema central circulatorio do osso e o sistema periferico, representado pelos vasos da epifise e do periostio. As anastomoses entre esses doị siștemas são precarias, muito especialmente ao nivel da metafise, ou zona da diafise subjacente á linha epifísaria. E' precisamente neste ponto que são mais frequentes as osteomielites.

Tambem por razões anatomicas, poderiamos explicar o fato que, sendo a medula ossea o ponto de eleição para a fixação. do processo infeccioso, este ganhe rapidamente o sistema conjuntivo dos sistemas de-Havers. Ochsner e Crile demonstraram que o calibre dos canais haversianos diminue rapidamente a partir de seu orificio interno ou medular ao seu orificio externo ou periostico. Esta constatação indica que os vasos dos sistemas de Havers são verdadeiramente os vasos terminais do sistema circulatorio da medula ossea. Supõe-se pois, que a infecção chegue sob a forma de pequenas massas microbianas, atingindo primeiramente o sistema haversiano. Sucede deste modo que a manifestação mais simples de uma infecção ossea é o fegmão intra-haversiano. As consequencias deste processo mixto, de inflamação e embolia no seio de um tecido limitado por paredes rigidas são as seguintes: 1) a obstrução dos vàsos haversianos pela propria embolia ou, pela hiperemia inflamatoria dá lugar á morte do osso ou necrose. Podemos formular como regra geral que não ha ostemielite sem̃ necrose ossea; 2) uma intensa hiperemia estabelece-se em torno da zona de osso necrosado. Esta hiperemia é, em parte inflamatoria, e em parte, devida a um infarto embolico. Como é natural, esta hiperemia manifesta-se claṛamente nas porções perifericas do faco que não estão encapsulizadas por uma trama rigida. Assim sendo, manifestar-se-á com toda a regularidade no periostio e na medula ossea.

Para haver a dilatação dos vasos intra-osseos é necessario que haja uma certa descalcificação das paredes dós canais de Havers. Efetivamente, esta descalcificação processa-se em torno dos vasos hiperemiados, sendo devida á mudança do $\mathrm{pH}$ sanguineo, neles contido, em consequencia, da acidose inflamatoria. Esta acidose local é responsavel pela chamada reaḅsorpção ossea em torno do foco de 
necrose: 3) a hiperemia e o edema periostio são condições predisponentes para a precipitação dos sais de calcio no seio do tecido periostal, dando lugar ao aparecimento de depositos calcareos á semelhança de grãos de areia que, aumentando progressivamente, chegam a formar um revestimento ao osso, isto é, ha uma ossificação periostal em toda a superficie do osso necrosado; 4) fenomenos semelhantes estabelecem-se na parte do osso situada para fora dessa zona de hiperemia. Como reação aos processos destrutivos instalados nessa zona de hiperemia, ha em toda a zona que rodeia o foco uma elevaçāo do $\mathrm{pH}$ sanguineo, que dá lugar á precipitação de calcio. Esta alteração traduz-se pela chamada - osteite condensante - , quer dizer, ha a formação de um osso mais compacto em torno do foco inflamatorio; 5) a medula ossea apresenta concomitantemente, o quadro de uma inflamação aguda, que pode ou não, ser acompanhada de uma fusão do tecido medular. Na generalidade dos casos, a medula tende a formar, em torno do foco inflamatorio, um tecido de granulação. Quando o processo inflamatorio osseo tende a regredir, este tecido de granulação infiltra-se atravez os condutos osseos dilatados, estabelecendo-se assim uma barreira de separação entre o osso
necrosado e o vivo.

Variedades de osteomielites - Todos estes fenomenos, ou sejam, necrose, hiperemia e reabsorpção ossea periferica, formação de uma camada periostal e conderisação ossea em torno das zonas de reabsorpção e, formação ás expensas da medula, de um tecido de granulação, associam-se em proporçōes variadas para formar os diferentẹs tipos de osteite observados em clinica.

Praticamente, podemos-distinguir dois tipos principais de uma osteomielite :

1 - Osteomielite primitivamente aguda, com tendencia a destruição, a supuração e a formação de sequestros, quer dizer, a mortificação de zonas inteiras de osso, que devem eliminar-se secundariamente como corpos extranhos, ás expensas do tecido de granulação.

2 - Osteomielites frequentemente denominadas $\longrightarrow$ osteites primitivamente cronicas - caracterizadas pela escassa tendencia á destruição do tecido osseo, em comparação com sua acentuada tendencia á calcificação periferica; esta calcificação periférica pode dar lugar á pode assim termino necrosado, como se fora um enxerto, e o processo

\section{OSTIOMIELITE AGUDA}

Toma-se como tipo para descrição da osteomielite aguda ou, osteomielite hematogenica infecciosa dos adolescentes, a osteomielite ção na metafise dos osso aparecimento na idade juvenil, sua localizagerais que podem acompanha-la. 
Patogenia - Onome de osteomielite hematogenica, com que tambem é denominada esta molestia, indica o mecanismo de sua produção; o germen causal é o estafilệcocus na maioria dos casos correntes, sobrevirdo em pleno gozo de saude, sendo que a sua porta de entrada é uma infecçãó cutanea. Geralmente, é um furunculo essa porta de entrada, tanto assim que já Pasteur dizia que "a osteomielite é um furunculo da medula ossea".

As osteomielites estreptococicas; muito menos frequentes, costumam ser precedidas de antecedentes frizantes, tais 'como', anginas, otites, etc. Finalmente, as osteómielites pelos bacilos tificos; pneumococus, etc., nãó se apresentam sinão no decurso ou então, durante a convalecença dessas infeções gerais.

Fatores etiologicos - a) Idade - Em $90 \%$ dos casos de osteomielite aguda, encontramos individuos menores de 15 anos. O maximo de incidencia da molestia, da-se entre os 10 e os 12 anos, quer dizer, numa idade ëm que o crecimento é particularmente ativo.

Não nos devemos esquecer, entretanto, que à osteomielite pode acometer crianças com menor idade e mesmo os adultos. De qualquer modo, apoz os 25 anos, é excepcional a osteomielite. O que se dá, com frequencia, no adulto e nos velhos,é o recrudecimento de uma osteomielite adquirida na infancia.

b) Sexo - Os meninos são duas veźes mais atacados que as meninas. Atribue-se este fato a que a pele dos meninos é geralmente mais suja e mais exposta a traumatismos e infecções do que aquela das meninas.

c) Traumatismos - Uma das causas da predisposição dos individuos do sexo masculino á osteomielite, é a maior frequencia com que se observam traumatismos. Estes, figuram efetivamente, nos antecedentes de numerosos casos de osteomielite e, sua conexão com a molestia, parece fora de duvida. Supõe-se que os traumas agem produzindo pequenas hemorragias sub. periostais que rompem. as ligaçõ̀es entre ar circulação medular e a periferica do osso.

d) Localizaçâa - Como referi, a oșteomielite juvęnil tem preferencia pelos ossos longos 'dos membros, particularmente para aqueles do membro inferior, dos quais o femur é o mais atingido.

A localisação nos ossos curtos é muito mais rara.

Nos ossos longos, o processo se localisa, na maioria dos càsos, na zona metafisaria, proximo á epifise mais fertil.

$\because$ Estes fatos e, a idade dos enfermos, sugerem a, idéia de uma correlação entre a osteomielite e o processo de crecimento-osseo. Corrobora ainda neste sentido o fato que a osteomielite dos adultos não manifesta preferencía especial por nenhum ossso, nem por nenhuma zona determinada dos mesmos. As infecções se apresentam aqui com igual frequencia, quer nos ossos longos como curtos. Ademais, a localisação diafisaria nos ossos longos é mais frequente que a metafisaria. 
Anatomia patologica - As lesões da osteomielite adquirem una complexidade crescente, conforme a intensidade do processo, mas sobretudo, com a extensão da infecção. Baseando-nos neste fato, podemos estabelecer varios tipos de lesōes que parecem corresponder a zonas cada vez maiores de embolisação septica, a saber:

1 - $O$ abcesso subperiostal, resultante de um flegmão haversiano simples. Os processos de necrose não atingem aqui, sinão as camadas mais superficiais do periostio e, apenas manifesta-se uma reação medular sob esse foco.

2 - $\mathrm{O}$ abcesso subperiostal comunicante com um foco de medulite supurada (abcesso em forma de botão); a necrose costuma atingir toda a espessura do periostio. Raramente existe um abcesso medular, sem haver concomitantemente um abcesso subperiostal.

3 - A necrose extensa de uma larga zona da diafise, correspondente ao territorio de distribuição de um dos ramos principais da arteria nutriente do osso.

A porção necrosada apresenta uma cor branca especial que ressoa de maneira caracteristica á percussão.

4 - A necrose em massa de toda a diafise, como se tivesse dado a obstrução do tronco principal da arteria nutriente. Os fenomenos se desenvolvem como no caso anterior, porem, com maior intensidade.

5 - Formação de focos multiplos no tecido esponjoso, com necrose das taboas osseas intermediarias. Este tipo de lesōes é caracteristico na osteomielite dos ossos curtos e chatos, porem, possivel existir algumas vezes, na metafise dos ossos longos. Neste caso, o processo pode romper a barreira que se opöe a ele, representada pela cartilagem de conjugação, irrompendo na epifise.

Sintomatologia - Nas formas de media gravidade, a osteomielite apresenta-se com o quadro geral de uma enfermidade infecciosa aguda. Assim é que se acompanha de calafrios, vomitos,' febre alta. Não demora a se instalar a dor, que se extende de inicio, a todo o membro, senda sempre mal localisada pelos doentes. A pressão do dedo, desperta viva dor em um ponto limitado do osso, que corresponde exatamente á séde do foco. Este sinal de dor, provocado numa zona muito limitada, no meio de uma dôr expontanea muito difusa, tem grande valor diagnostico.

Os sinais locais da inflamação, aparecem imediatamente apoz. No principio, todo o membro se edemacia; não tarda porem, que se note no meio do edemaciamento, uma zona juxta-articular, na qual a pele está particularmente tumefeita, arroxeada, brilhante e sulcada de veias dilatadas. Neste momento, a palpação pode apreciar um empastamento profundo, porem, somente dias apoz surge nessa zona, uma flutuação caracteristica. Para que a flutuação seja apreciada nitidamente, é necessario que o puz tenha transbordado para fora do periostio, quer dizer, o processo atingiu uma fase tão avançada, que põe em perigo o membro do paciente. 
A abertura natural ou cirurgica da coleção purulenta, produz sempre um alivio da dor e dos fenomenos gerais, persistindo porem uma supuração que pode prolongar-se mezes, e mesmo anos. Nestas condições, uma ou varias fistulas se abrem, fecham-se e voltam a se abrir. Explorando-as com um estilete, percebe-se no fundo, a sensação inconfündivel de um sequestro.

A supuração é mantida nestes casos, pela presença do sequestro; trata-se de uma verdadeira supuração por corpo extranho.

Nas formas com focos multiplos no tecido esponjoso, as fistulas eliminam, de quando em vez, pequenos sequestros, Estes, contrariamente ao que se dá nos ossos longos, pequena influencia exercem sobre os processos supurativos.

Formas clinicas - Pela intensidade dos fenomenos gerais, distinguem-se as seguintes formas:

1 - Forma hiper-aguda. - Manifesta-se por um quadro geral extremamente grave desde os primeiros momentos. A temperatura é elevada e o pulso, irregular. Este quadro corresponde localménte, ao tipo de mortificação maciça do osso. $\mathrm{Na}$ realidade, tratá-se nestes casos, de uma infecção geral piogena que conduz á morte na maioria dos casos. $\mathrm{O}$ exito letal ocorre geralménte entre $\sigma$ terceiro e o quarto dia.

2 - Forma septicemica. - Assume o quadro comum ás osteomielites agudas mạs, com diminutas nianifestações locais. A abertura do foco manifesta que os processos necroticos são muito extensos, porem, a supuração é diminuta.

Os fenomenos gerais persistem, acehtuando-se com o decorrer dos dias, tomando caracter toxico muito acentuado; ha palidez, pulso fraco e irregular, estado tifico. Atribuem-se estes casos a infecções gerais por estreptococus hemoliticos. Esta forma termina pela morte do paciente, geralmente ao fim de 15 ou 20 dias ; na generalidade dos casos, é precedida pélo quadro de una endocardite maligna.

Segundo a idade, podemos distinguir os seguintes tipos de osteomielite:

a) A osteomielite dos lactantes, quasi sempre acompanhada de manifestações piemicas. Não somente aparecem focos de supuração em varios ossos, mas tambem nas articulações e sob a pele. Apesar de. não ser uma forma grave, este tipo de ostiomielite depaupera excessivamente os enfermos.

b) -A ostiomielite dos adultos, acompanhada unicamente de manifestações gerais. $\mathrm{Na}$ maioria dos casos, acusa-se unicamente pela dor que os doentes localisam mal, e a atribuem quasi sempre a reumatismo.

Pela localisação, podemos distinguir os 'seguintes tipos de osteo-, mielite:

a) As osteomielites dos ossos chatos, que costumam dar lugar 'a multiplos focos que se extendem progressivamente ao longo da 
diploe desses ossos. Este fato faz com que estas osteomielites se prolonguem no periodo subagudo $e$, se tornem extremamente rebeldes ao tratamento.

As formas assestadas nos ossos do craneo são particularmente graves porque, no decurso de sua evolução, costumam produzir a infecção dos orgãos intracranianos.

b) As osteomielites dos ossos curtos, que costumam produzir a necrose em massa dos mesmos, com invasão das articulações visinhars.

A localisação vertebral, si bem que rara, é quasi sempre fatal.

Complicações - A artrite supurada e a infecção geral piogena são, por assim dizer, as unicas complicações imediatas da osteomielite.

As complicações á distancia são:

1 - Defeito no crescimento dos ossos, devido a perturbações na evolução das epifises osseas.

2 - A deformação da diafise dos ossos, que foi substituida em maior ou menos extensão pela neoformação periostal.

3 - Crescimento exagerado dos ossos, em consequencia da irritação formativa exercida pela osteomielite proximo á cartilagem epifisariá.

4 - Perda de substancia consecutiva á mortificação em massa de um grande segmento osseo.

Diagnóstico - E' do mais alto interesse faze-lo nos primeiros momentos do mal, pois é quando existe a unica possibilidade de aborda-lo. Na realidade, não é dificil fazer-se esse diagnostico, si se tem presente a possibilidade de una osteomielite quando' se está em frente a um quadro de infecção geral, com dores nos membros, infecção essa que surge na segunda infancia.

Dos meios que se lança mão para esse diagnostico, o exame radiografico, si bem que de pouca valia no inicio da afecção, é um auxiliar precioso quando a osteomielite está em face mais avançada, permitindo-nos evidenciar a extensão do processo.

Os exames de sangue, são imprecindiveis, não somente para o diagnostico de supuração, como tambem para avaliarmos do grau de toxicidade da infecção.

As osteomielites cronicas, fistulosas podem ser confundidas com a tuberculose ossea. A radiografia é aqui o auxiliar mais precioso de que dispõe o clinico para o diagnostico diferencial. Em vez de uma imagem de descalcificação difusa, caracteristica da tuberculose, notamos no decurso da osteomielite, sombras compactas e nitidamente separadas dos sequestros, no meio de zonas de reabsorpção ossea claramente desenhadas na radiografia.

Tratamento - Como vimos no inicio dessa explanação, a osteomielite se caracterisa de inicio pelo aparecimento de um abcesso no osso atingido. O tratamento consistirá, em razão desse fato, na 
abertura do foco o mais cedo possivel. Diz-se com inteira razão, que, si a tempo que medeia entre o começo da molestia' e'a intervenção é medidó por horas, a convalecença medir-se-á por semanas; si esse tempo é calculado por dias a convalescença medir-sé-á por mezes e mesmo anos.

A evacuação precoce do puz melhora, evidentemente, as condiçôes circulatorias dentro do foco e é, consequentemente, o melhor meio de evitar necroses extensas. Na maioria dos casos, o puz coleta-se sob o periostio e basta, para tanto, a abertura deste para se lograr a drenagem. A incisão deverá ser praticada no ponto mais doloroso á pressão, que geralmente possue uma locạlisação tipica em cada osso.

Nos primeirós momentos, devemo-nos limitàr a essa incisão, que não deve ser seguida de tamponamento com gaze, pois é absolutamente necessario evitar a compressão ou o traumatismo dos tecidos. Tambem, é prejudicial nesse periodo precoce da molestia, a trepanação, que não somente açarreta um serio traumatismo, como pode contribuir diretamente para a propagação do processọ. Em contraposição, uma vez insțalada a supuração na medula, a trepanação se impóe. Conforme a quantidade de puz que emerge atravez de um primeiro orificio praticado com 0 trepano, deixar-se-á essa unica abertura ou abrirr-se-á uma janela com um formão.

Ráramente, é necessario ampliar mais essa abertura, particularmente quando se intervem de modo precoce: Entretanto, quando a intervenção é tardia; o processo já não mais pode ser detido, mesmo ás custas de maiores operações. Assim mesmo, nos casos hipertoxicos nada se consegue com a pratica de intervençôes radicais.

A intervenção retardada, apoz a abertura expontanea ou cirurgica do foco, pode ser exigida para melhorar e facilitar a evacuação. de um foco insuficientemente drenado. Em geral, convem deixar-se tudo como está, até que haja libertação do sequestro é a supuraçã̃o. seja évidentemente mantida por ele. Mesmo neste caso, convem evitar qualquer intervenção; o maximo que se pode fazer, é procurar orientar o sequestro na direção da fistula, extraindo-o atravez dela.

Ápoz a eliminação do sequestro, perduram no osso, grandes. càvidades que mantem ativo o processo de supuração; é então que 'se indicam operações remodeladoras. Algumas vezes, consegue-se desta maneira, por cobro a supurações antigas, o que aliạs nem sempre dá bons resultados.

Tem-se tentado as autoplastias com pele e com musculos, com o intuito de preencher os grandes seios osseos. No que diz respeito á pluníbagem ou enchimento dessas cavidades com massas diversas (cera de dentistas, parafina, etc.) ou com materiais organicos (musculos, sangue, gordura), fracassa na maioria das vezes.

Recentemente, foi proposto por Orr. um tratamento que parece jugular o decurso das fistulas: Consiste este metodo em tamponar 
com gaze vaselinada, as aberturas cirurgicas ou expontaneas que conduzem ao foco osseo e, colocar o membro atingido, num aparelho de gesso, durante alguns mezes. Durante este tempo, as aberturas supurantes permanecem banhadas no proprio puz, facilitando o desenvolvimento de germens, que alcalinizam o meio, tornando desfavoravel o desenvolvimento dos piogenos. Muitas vezes, ao se retirar o gesso, percebe-se que as fistulas estão preenchidas por um tecido de granulação, que as faz cicatrizar em pouco tempo. Constitue esse tratamento, uma modalidade da cura retardada da osteomielite.

Bier e sua escola, tratam as fistulas osteomieliticas, mediante a cauterização profunda do foco e o fechamento primitivo por uma sutura. Os argumentos em que se fundamenta este ultimo tratamento, tem contra si numerosas objeções.

O tratamento geral pelos sôros pode ser ensaiado nas formas toxicas estreptococicas, isto não querendo dizer que se exclua o tratamento cirurgico. O mesmo pode ser dito da quimioterapia e da auto-hemoterapia.

Devo citar ainda a chamada vacinação arterial de Borelli, feita com a vacina de Delbet.

Uma outra terapeutica preconisada é aquela por intermedio de. larvas de moscas, cultivadas em meios acepticos e semeados no foco de infecção. Essas larvas, aí crescendo, alcalinizam o meio, o que facilita a cura do processo. Um outro tratamento, baseado neste metodo antiquado, é pelo emprego da permease gelatinada, aplicadá sobre o proprio foco de infecção.

\section{CÁSA DE SAUdE D. PEDRO II} CIRURGIA - MATERNIDADE - ORTOPEDIA

Aberta a todos os medicos

Rua Figueira, 8 - Tel. 3-3141 (Parque D. Pedro II) 
O Departamento Biológico dos Laboratorios Ancona Lopez Soc. Ltda., tendo como consultor científico o Dr. J. Travassos, apresenta à distinta classe médica brasileira o seu produto:

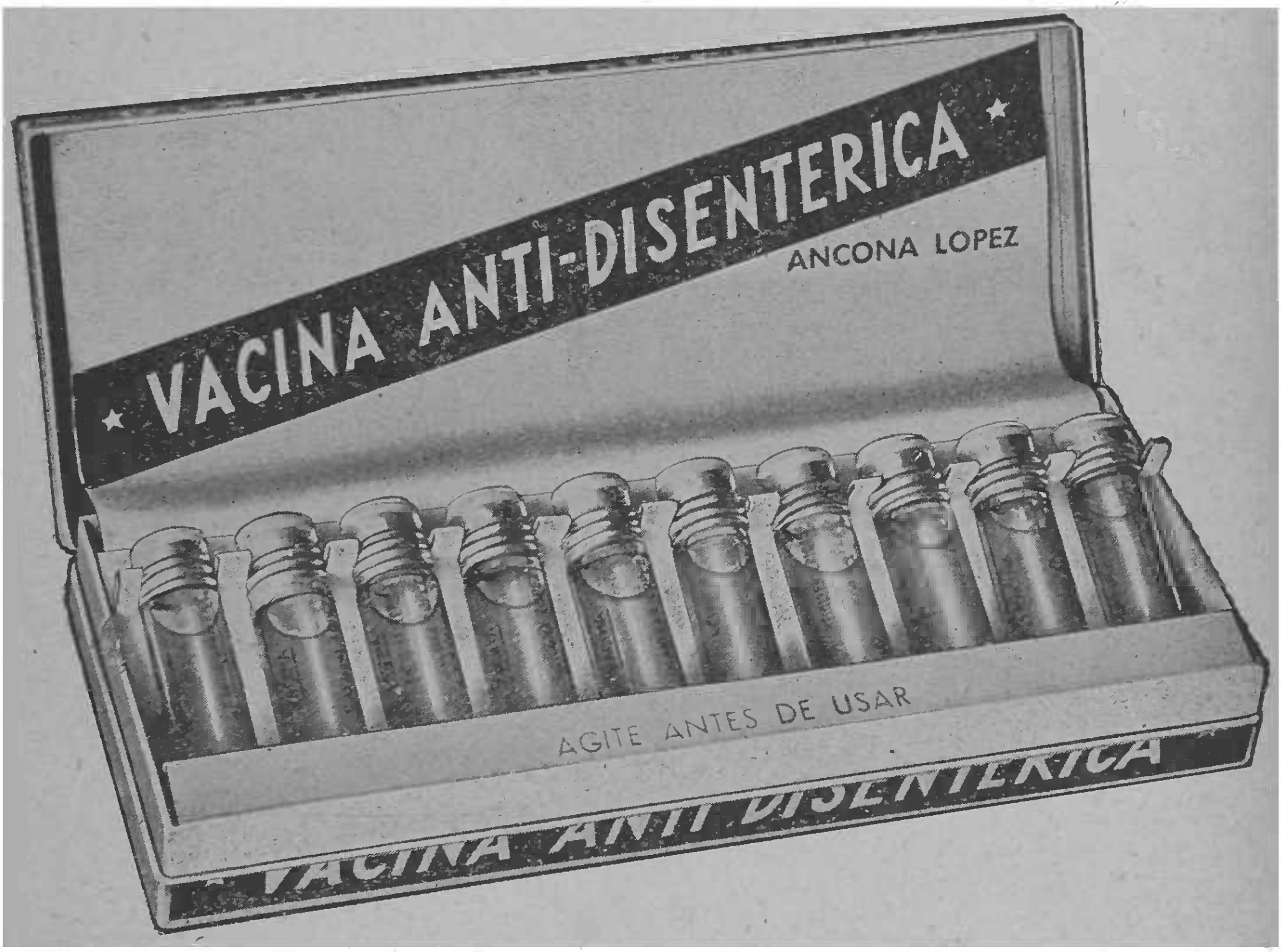

VACINA ANTI-DISENTERICA

Enterites, Entero-Colites de natureza infecciosa bacilar

Amostras e literatura à disposição dos Senhores Médicos LABORATORIO ANCONA LOPEZ SOC. LUTDA.

Laboratorios

R. Augusta, 1.426

Fone: 7-7266
Dep. Propaganda

R. Boa Vista, $15-3 .^{\circ}$ Andar

Fone: 2-0680 


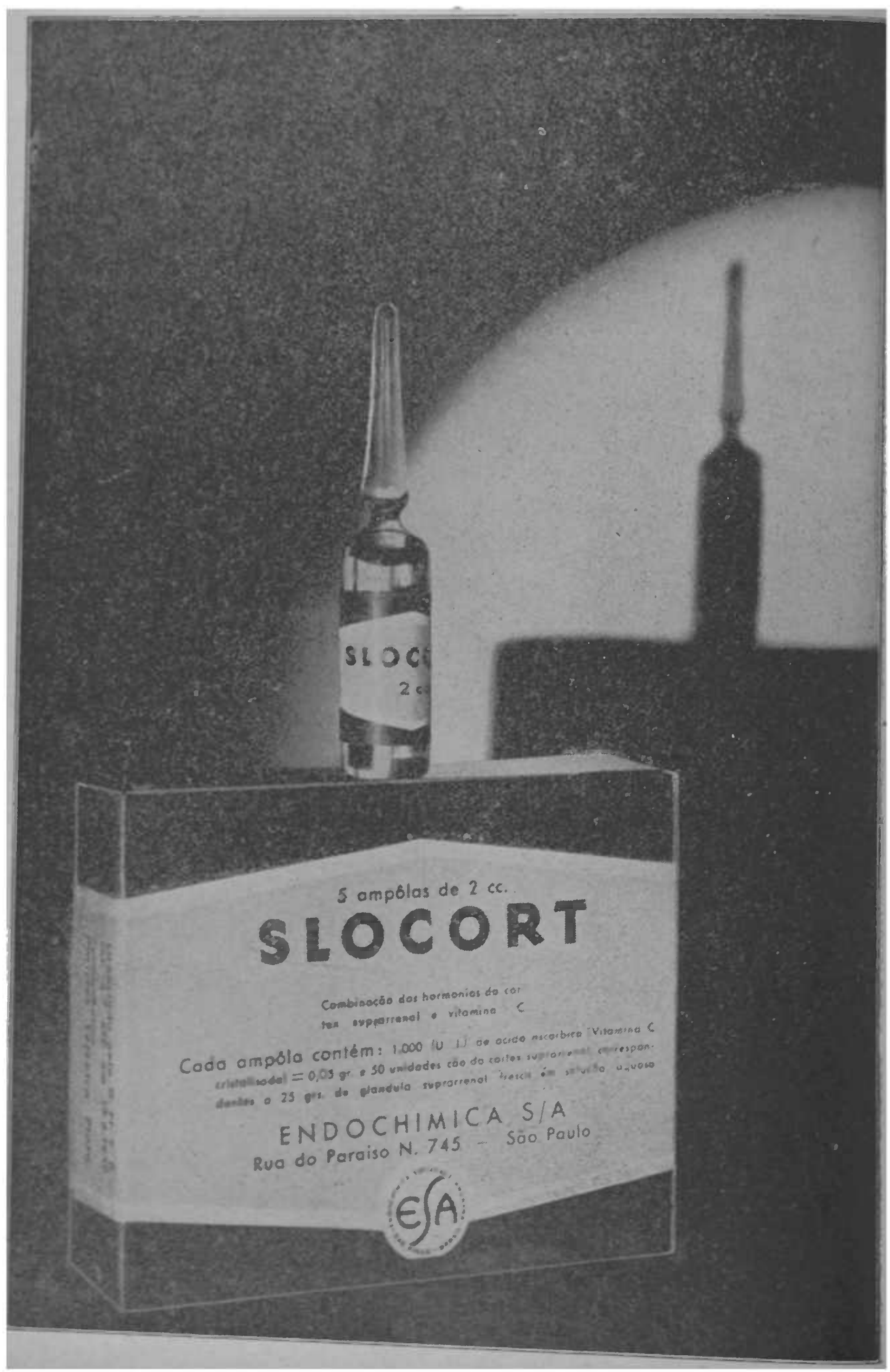

